\section{Jesus tem dentes metal-free no país dos banguelas?: odontologia dos desejos e das vaidades}

\section{Does Jesus have metal-free teeth in a country of the toothless?: dentistry of vanities and desires}

Adauto Emmerich

Professor de saúde bucal coletiva do curso de Odontologia e do Programa de Pós-Graduação em Saúde Coletiva Universidade Federal do Espírito Santo

Av. Marechal Campos, 1.468 29040-090 - Vitória - Espírito Santo - Brasil

adautoemmerich@terra.com.br

\section{Luis David Castiel}

Pesquisador do Departamento de Epidemiologia da Escola Nacional de Saúde Pública / Fundação Oswaldo Cruz Rua Leopoldo Bulhões, 1.480, sala 802 21041-210 - Rio de Janeiro - RJ - Brasil castiel@ensp.fiocruz.br

Recebido para publicação em setembro de 2006. Aprovado para publicação em julho de 2008.
EMMERICH, Adauto; CASTIEL, Luis

David. Jesus tem dentes metal-free no país dos banguelas?: odontologia dos desejos e das vaidades. História, Ciências, Saúde Manguinhos, Rio de Janeiro, v.16, n.1, jan.-mar. 2009, p.95-107.

\section{Resumo}

Descreve como a odontologia atual, no Brasil, participa das transformações do objeto de sua atividade em mercadoria para os consumidores darem vazão a desejos estéticos. Explora a construção do objeto odontológico dos desejos e sua relação com o cirurgião-dentista e o paciente-consumidor no mundo contemporâneo. Explicita o papel dos megacongressos odontológicos, a propiciarem um self-service biotecnológico que enfeitiça e seduz, uniformizando valores consumistas para a avidez por novidades dos cirurgiões-dentistas. Analisa a atuação da mídia na prática odontológica. Conclui que a individuação do cirurgião-dentista gerou ontologia petrificada e epistemologia fragmentada, apresenta algumas tarefas inadiáveis para os segmentos acadêmico-profissionais e a sociedade, como o desenvolvimento de estratégias e a discussão sobre a comunicação em saúde bucal.

Palavras-chave: saúde bucal coletiva; odontologia dos desejos; objeto coletivo; biotecnologia.

\section{Abstract}

This paper describes how dentistry in Brazil currently participates in the transformations of the object of its activity into commodities with which consumers can indulge their aesthetic desires. It explores the construction of the dental object of desires and its relationship with the dentist and the patient-consumer in the contemporary world. The paper makes explicit the role of the mega-dental congresses, which provide a biotechnological self-service that allure and seduce, creating uniform consumer values eager for the new offerings from dental surgeons. Also analyzes the role of the media in dental practices. It concludes that the individuation of the dental surgeon has generated a petrified ontology and fragmented epistemology. The paper presents some pressing tasks for the academic and professional sectors and society as a whole, such as the development of strategies and discussion about communication related to oral health.

Keywords: collective oral health; dentistry of desires; collective object; biotechnology 
$\mathrm{R}$ efletindo sobre a odontologia atual no Brasil, analisaremos criticamente seu desenvolvimento biotecnológico e sua participação nas transformações do objeto de sua atividade em mercadoria para os consumidores darem vazão a seus desejos e vaidades estéticos. Para entender a prática odontológica, é necessário deslindar a teia de relacionamentos da qual emerge seu objeto. Por isso, propomos investigar as relações institucionais e sóciohistóricas da odontologia com seu objeto e a sociedade contemporânea.

A expressão sócio-histórica aqui utilizada não é nem a adição indefinida dos entrelaçamentos inter-subjetivos dos cirurgiões-dentistas, ainda que o seja também, nem, certamente, seu simples produto. É aquilo que Castoriadis (1986) definiu como o coletivo anônimo, o humano-impessoal que preenche toda formação social dada, que insere cada sociedade em meio às demais, e as inscreve todas em continuidade na qual, de certa maneira, estão presentes os indivíduos que não existem mais, os que estão em toda parte e mesmo os que estão por nascer. Abrange, por um lado, estruturas odontológicas dadas, instituições e obras materializadas e, por outro lado, analisa o que estrutura, institui, materializa a prática odontológica. Nessa medida, trata-se de compreensão interpretativa da produção social e biotecnológica do cirurgião-dentista para atender à paixão dos consumidores relativa à odontologia estética. É a união da prática odontológica produzida com a que está se fazendo na sociedade contemporânea, e sua tensão, buscando aumento da compreensão do problema.

Existe, na odontologia, um magma de significações que dá funcionalidade e conexões à criação de cada época histórica, porém não é pretensão deste ensaio sugerir nova episteme sobre a prática e o objeto odontológicos. Queremos apenas debater a respeito das relações decorrentes da transformação do objeto na sociedade contemporânea, cujos protagonistas são os atores sociais da formação odontológica e os consumidores-pacientes.

Hoje, o atraente e moderno fórum científico da odontologia é formado pelos gigantescos congressos odontológicos clínicos, de forte influência do capitalismo consumista e em que são disponibilizados produtos biotecnológicos, provenientes principalmente dos países do primeiro mundo, cuja investigação científica situa-se nas mãos da indústria, à margem das instituições educativas e de serviços (Payares González, 1997). Nesses espaços, o cirurgiãodentista produz e reproduz uma ontologia petrificada contemporânea de práxis hegemônica de concepção de mercado. Castoriadis (1986) faz crítica pertinente a essa ontologia em relação à realidade sócio-histórica, procurando desvelar a dimensão do desenvolvimento do ser e sua prática como uma criação contínua do homem dirigida ao outro, como a um ser autônomo, no sentido de que ninguém poderia seriamente desejar a autonomia sem a estender a todos. Observamos aqui um ponto de partida para aumento da compreensão do objeto e da práxis odontológicos, não excludentes, mas inclusivos quanto ao outro (consumidor-paciente), com sentido e desejo coletivos.

\section{Objeto em questão}

As várias contribuições que instituem os fenômenos do cirurgião-dentista e a interioridade de relações com seu objeto, bem como sua complexidade, situam-se ao longo do tempo em vários planos e espaços sociais e científicos que podemos considerar o mundo da vida 
odontológica. Como observa Castiel (1999), identificamos o mundo da vida tal como se apresenta para cada um de nós, como a resultante singularizada de complexas configurações bioquímicas, psicológicas, socioculturais, em que o estabelecimento e as tentativas de reordenação da idéia de 'si-mesmo' são frágeis e dependem de contribuições genéticas, construções epigenéticas, biografia pessoal, estrutura psicológica inconsciente, elementos culturais e acaso. Nesse mundo, o ordenamento do cirurgião-dentista, seu objeto, a idéia de si mesmo e sua dimensão subjetiva foram-se estabelecendo com suas referências e opções clínicas que o configuram como fenômeno complexo na sociedade contemporânea. Como ilustração, num ponto remoto do passado pré-histórico, Coppa et al. (2006) identificaram que há 9.500 anos, durante o período Neolítico, aldeões paquistaneses usavam brocas de pedras para abrir buracos nos dentes, sendo um dos primeiros registros mundiais de atividades supostamente 'odontológicas' com um tipo de proto-dentistry.

É essencial considerar que em seus primórdios, a odontologia, mesmo que empírica, foi politicamente isolada pelo poder do escolasticismo medieval, doutrina teológico-filosófica que juntou às leis da razão a teologia como ciência, tendo consolidado a criação das primeiras universidades, incluindo as escolas médicas sem a assimilação da prática odontológica existente (Le Goff, 1988). A Igreja, entretanto, via com profundo desprezo o trabalho manual das corporações dos barbeiros e dos cirurgiões, impondo proibições com o interdito "ecclesia abborret a sanguine" (aborrecimento da Igreja com o sangue). Esse fato histórico deve ter contribuído para e dinamizado o processo de individuação do saber e objetificação do trabalho odontológico a posteriori. Para Schapira (set.-dez. 2003), a hegemonia e o prestígio usufruído pela prática médica em sua institucionalização na Argentina, implicou sua expansão permanente, expressada na subordinação dos chamados 'ramos menores', a odontologia entre eles.

No Brasil, trazida pelos portugueses, a odontologia era exercida inicialmente pelos barbeiros-cirurgiões, e, com sua institucionalização em 1884, no Rio de Janeiro e na Bahia, começaram formar-se os cirurgiões-dentistas. As disciplinas implantadas sob o vezo positivista eram completamente desprovidas de preocupações sociais, em relação ao adoecimento humano, tecnicistas e biologicistas, com ênfase naquilo que pode ser expressado e medido (mecanicistas). Tendo havido uma ruptura nesse processo, o barbeiro-cirurgião seguiu sua trajetória até os dias atuais, 'materializando-se' sob os codinomes de falsos profissionais ou dentistas práticos, que atendem até hoje às parcelas de nível socioeconômico mais baixo (Emmerich, 2000).

A influência da medicina científica na era do capitalismo industrial amalgamou-se de forma marcante à formação odontológica no Brasil, em suas reformas curriculares, com raízes também positivistas, cientificistas e pragmáticas. A prática odontológica passou, então, a ser conhecida como 'odontologia científica ou flexneriana' (Meira, 1985), individualista, biologicista e mecanicista, considerando a boca parte de um corpo, fragmentando o saber odontológico.

Com a conseqüente tecnicização do ato odontológico, passou-se a considerar padrão de boa qualidade os procedimentos realizados com equipamentos de alta sofisticação, com lócus urbanocêntrico, exclusão de práticas alternativas e essencialmente curativos, sendo essa lógica epistemológica denominada por Narvai (1994) 'odontologia de mercado'. 
Esses fenômenos que materializam a ciência odontológica não são o mero ponto de encontro de ações e coisas em si produzidas em suas etapas evolutivas. Neste caso, não usamos um modelo polarizado para esta abordagem. Aqui nos apoiamos na idéia de Latour (1999) de que os fenômenos são aquilo que circula ao longo da cadeia histórica reversível de transformações, perdendo a cada etapa algumas propriedades e ganhando outras. De acordo com a categoria 'referência circulante' (Latour, 1999), jamais se conseguirá constatar a semelhança entre a mente e o mundo, que poderá, entretanto, ser estendida à cadeia de transformações sempre que uma referência verificada circular ao longo de substituições constantes.

É impossível recuperar a sucessão de etapas e referências em que o objeto odontológico foi-se construindo. No que foi possível rastrear, nosso olhar foi deslocado de forma fragmentada no sentido de sua evolução até hoje. Assim, a verdade absoluta da forma como o objeto odontológico está constituído apresenta incompletude nesse ato de apontar suas referências na longa cadeia de sua transformação. O que fazemos é retomar algumas referências que circulam até hoje, como a individuação do trabalho odontológico e sua referida objetificação nos dentes.

A recuperação do homem por inteiro, para um objeto odontológico coletivo e com dimensão pública e socializada, fortalecendo o campo da saúde bucal coletiva, é apenas uma das elaborações teóricas deste ensaio, pois a práxis odontológica sempre foi hegemonicamente enclausurada em quatro paredes, assumindo seu objeto particularmente pela perspectiva do cirurgião-dentista e do paciente. Não pensamos que seja solução uma ruptura epistemológica entre a saúde bucal coletiva e a odontologia tradicional de mercado, como sugere Narvai (2001), pois, concordando com Latour (1999), realistas, empiristas, idealistas e racionalistas de todo o gênero digladiaram-se incansavelmente à volta do modelo bipolar sobre a relação entre as coisas e os objetos, sem levar em conta a cadeia de transformações, etapas subseqüentes no processo histórico.

A redução do indivíduo à boca e a seus dentes, priorizando suas doenças e suas especificidades biológicas e sistêmicas, vem fecundando, no meio odontológico, um debate com várias concepções epistêmicas sobre o objeto e o cirurgião-dentista: a medicina oral (Siverman, Eversole, Truelove, 2004), interdisciplinar, multiprofissional e biopsicossocial, medicina periodontal (Offenbacher, Beck, 2004), bucalidade (Botazzo, 2006), odontologia de mercado (Narvai, 1994), saúde bucal coletiva (Narvai, 2001), que buscam discutir e/ou fazer emergir uma nova práxis e proposta cognoscente odontológica.

O debate deve ser ampliado em função da luta pelo poder internalizado na odontologia e pela credibilidade das disparidades conceituais explicitadas. A prática odontológica atual é herdeira da tradição sócio-histórico-odontológica e, por mais que se queira fabricar discurso de objeto odontológico coletivo, sistêmico, individual ou paradigmático, a questão essencial que está colocada é ainda a profunda individuação do trabalho e da odontologia numa perspectiva ainda bastante centralizada em quem produz o objeto odontológico, o cirurgiãodentista.

Sendo a percepção do objeto odontológico e do homem criação de cada época histórica, tomemos como exemplo o caso da formação do cirurgião-dentista na graduação. Ao ter como seu auxiliar outro colega, e não um técnico em higiene dental ou um auxiliar de 
consultório dentário, o processo de formação é centrado no cirurgião-dentista e seu consultório, tendo, ao se 'olhar num espelho', visão única de sua prática, de seu eu, que circula em torno de si mesmo, estando alhures da possibilidade de construção socioodontológica operada pelos trabalhadores da saúde bucal e pela sociedade.

Entretanto, a fim de compreender melhor o objeto odontológico na sociedade contemporânea, o 'narcisismo odontológico' e seus novos significados internalizados, a odontologia dos desejos e das vaidades entra em cena com o consumidor-paciente, ator que protagoniza e estimula o culto ao corpo e a estética bucal, induzindo transformações no objeto em questão.

\section{Objeto 'hollywood smile'}

A obsessiva vaidade dos consumidores de tratamentos estéticos odontológicos está produzindo uma odontologia sem fronteiras, sem crises nem recessão econômica, com mercado aberto e crescente. Agora os novos consumidores contribuem para que o objeto odontológico de seus desejos, perfeito, magnífico, sem problemas, lhes garanta um 'hollywood smile', procurando os cirurgiões-dentistas e fornecendo o diagnóstico de suas necessidades bucais estéticas. Para os consumidores com poder aquisitivo e o setor médico-odontológicoindustrial, a odontologia atual caminha para uma prática biotecnologizada, com implantes dentários, novas possibilidades de reabilitação cirúrgica bucal funcional e principalmente estética.

Do começo ao fim, sempre se estará diante do esforço de propor um sucedâneo artificial, uma construção fabricada, em substituição a uma parte dentária que se foi. Com o avanço biotecnológico, o objeto odontológico, segundo Sharpe e Young (2005), é um pouco mais complexo do que parece, configurando um conjunto de pequenos órgãos. Esses autores desenvolvem estudos avançados sobre a produção de dentes humanos bioengenheirados, o que não passava de sonho até bem pouco tempo atrás. Os progressos quanto à compreensão do desenvolvimento dentário, combinados com avanços da biologia de células-tronco, bem como da tecnologia da engenharia tecidual, nos aproximaram da realidade dos dentes biológicos de substituição. É claro que ainda existe muito chão pela frente, mas a produção de dentes protéticos vivos - dentes de proveta - poderá colocar a odontologia na era da medicina regenerativa e, de quebra, abrir caminho para a engenharia de órgãos maiores.

Nas últimas três décadas, os congressos odontológicos clínicos tornaram-se novo 'espaço sociocientífico', configurando-se como verdadeiro 'self-service biotecnológico'. A odontologia, em sentido mais ampliado, além das instituições acadêmicas, revelou-se portadora de nova identidade, pois transformou a vetusta 'arte dentária' em arte voltada para satisfazer o desejo e a vaidade dos consumidores, com objeto dirigido a novos tipos de existência, de valores e representações sociais. Desse modo, a práxis odontológica, com nova formamercadoria, inseriu-se na era do capitalismo consumista em que se procuram a novidade, o moderno, o que nunca se teve, e, assim, o desejo de ter revela-se permanente desespero, pois aquilo que é novo está sempre se transformando.

Outro mecanismo que influencia a prática odontológica atual no Brasil e vem participando das transformações de seu objeto em mercadoria é a mídia, de modo geral, e a 
grande rede mundial (Internet). Estímulos variados são lançados diariamente para atender aos anseios estéticos dos consumidores voltados para a área da medicina estética. Por exemplo, no âmbito da odontologia, há revistas especializadas em plástica e beleza, e, no portal http://plasticaebeleza.terra.com.br/default.asp, os consumidores têm acesso a matérias jornalísticas informativas, sedutoras e atrativas com expressões de efeito como "sorriso de sucesso", "sorriso perfeito", "plástica no dentista", "odontologia cosmética", "restauração hollywood smile" e "metal free", "odontologia high tech", "clareamento a laser", "prótese em cerâmica alemã", "técnica cirúrgica all-on-four", enfim, uma 'odontologia sem fronteiras', como referem algumas comunicações. Trata-se do culto exagerado ao mito da felicidade, da sedução e da estética, como caminho para o sucesso.

Esse marketing poderoso é manipulado por profissionais, visando ao lucro e ao componente médico-odontológico-industrial, formado pelas megaindústrias que, em parte, fazem propaganda enganosa, com resultados duvidosos, e que estão invadindo todos os espaços odontológicos em busca de mercado e seduzindo os futuros novos profissionais via produção de conhecimento etnocêntrico, que 'entra pela janela' nas instituições universitárias brasileiras. Como exemplo, o uso do laser para o clareamento dental, enfatizando seu aspecto 'high tech'; sabe-se, porém, que ele não dispensa complementação com a técnica convencional de clareamento.

O poder da mídia, de acordo com Martin-Barbero (1997), só é pensável a partir da compreensão da nova revolução da sociedade de consumo, que vem liquidando a velha revolução operada no âmbito da produção. Como função mediadora, usam-se os meios de comunicação de massa, por exemplo, os programas de televisão matinais que promovem e divulgam principalmente os tratamentos odontológicos estéticos. Nem a família, nem a escola, nem as instituições acadêmicas, que poderíamos chamar de 'velhos redutos da ideologia', são espaços de possível socialização e da cultura de massa odontológica. Agora, os novos espaços e 'mentores intelectuais' são os filmes, a televisão, a publicidade, a rede eletrônica, que seduzem influenciando o modo de vestir e terminam provocando uma metamorfose dos aspectos éticos e morais mais profundos dos indivíduos/consumidores.

Sennett (2006), entretanto, aponta que a paixão consumista pode ser aquela que se extingue em sua própria intensidade, pois a utilização dos objetos os consome. Assim, a transformação do espaço social, do ponto de vista político e com imposição econômica, produz uma forma diferente de socialização e de consumo. Como ilustração, na parte comercial dos congressos odontológicos clínicos, são expostos e divulgados enfaticamente os novos produtos, as novas biotecnologias e os novos designs de equipamentos odontológicos, que induzem os cirurgiões-dentistas a adotar comportamento que os levará ao sucesso e à realização profissional. Esses congressos, com seus estandes de venda extremamente atraentes, com o look das garotas-propaganda e o glamour das novidades, de alguma forma contribuem para a construção da racionalidade individualista do cirurgião-dentista e sua nova 'identidade-objeto'. Eles operam por sedução e se apóiam na mimética propagação de uma socialização de valores consumistas e mercadológicos (self-service biotecnológico).

É nesse espaço que a forma-mercadoria odontológica se consolida na sociedade contemporânea, e o culto ali instituído ocorre pela apelação ao sucesso, pois quem não 
adere ao novo se torna obsoleto e, invariavelmente, fadado ao fracasso. Quaisquer que sejam os novos modos de atrair pacientes, de facilitar o sucesso, nada melhor do que pelos prazeres da vida. "Qualidade de vida (e os grandes prazeres) começam pela boca. Cuide dela" (Qualidade de vida..., jun. 2005). Assim um anúncio profissional-odontológico refere-se à saúde bucal, junto da imagem de um homem e uma mulher que se beijam apaixonadamente - uma das faces em que o objeto odontológico se ajusta à forma mercadoria sedutora para atender aos consumidores.

Ademais, Lipovetsky (2004) desenvolveu a comparação lógica de quanto mais a sedução se manifesta, mais as consciências aderem ao real, e quanto mais o lúdico prevalece, mais o éthos econômico é reabilitado. Daí podemos depreender que a sedução está integrada racionalmente à moderna odontologia e às novas lógicas da sociedade capitalista (capitalismo de consumo), visando atender aos anseios estéticos dos consumidores. No mundo moderno, seus procedimentos operatórios transformam-se com os novos materiais, por exemplo, na utilização da expressão metal free - dentes de porcelana ou resina sem utilização de ligas metálicas, de efeito estético muito interessante, mesmo não sendo tão resistente como as restaurações metálicas (entre as quais o vilipendiado amálgama de prata).

Até o advento das resinas compostas, na década de 1970, havia poucos tipos de resina; agora há uma centena, e ainda são lançados, quase a cada ano, tipos diferentes, com variações tecnológicas e, mais recentemente, a resina composta nanoparticulada. Um exemplo de como as mudanças são manipuladas e direcionadas ao éthos econômico está no jornal eletrônico Ciência em Dia (9 maio 2006) - blog do jornalista Marcelo Leite, que é também colunista do jornal Folha de S. Paulo -, que publicou excelente resenha sobre o uso do amálgama na odontologia (Leite, s.d.), dando razão e comentando o artigo do médico Ben Goldacre, colunista do jornal britânico The Guardian, que assina a seção Bad Science (Má Ciência), na qual espinafra as muitas lendas sem lastro científico ou empírico que se propagam como vírus pelos meios de comunicação sobre a fama de vilão do amálgama na odontologia (Goldacre, s.d.). Ao partir para a reabilitação do mercúrio utilizado nas antigas restaurações de amálgama, Goldacre observa, e com muita razão, que nenhum meio de comunicação deu destaque ao primeiro estudo publicado (Bellinger et al., 2006) que usou a metodologia, que se diz consagrada pela medicina, baseada em evidência para procurar dirimir a questão.

Acessamos a pesquisa de Bellinger et al. (2006), da qual participaram 534 crianças de seis a dez anos, atendidas em clínicas dentárias de Boston. Foram aleatoriamente distribuídas em dois grupos - um teve suas cáries obturadas com amálgama, o outro recebeu obturações de materiais livres de mercúrio. Os grupos foram acompanhados por período mínimo de cinco anos, para registro de eventuais diferenças nas funções neurológicas e renais. Muito embora as crianças do primeiro grupo tenham apresentado níveis 50\% mais altos de resíduo de mercúrio na urina ( 0,9 micrograma por grama de creatinina, contra 0,6 no outro), elas não mostraram diferença estatisticamente significante de desempenho em testes de raciocínio, memória e visão, nem no funcionamento dos rins. Os autores concluem que, embora seja possível que efeitos muito pequenos no QI não possam ser excluídos, esses resultados sugerem que os efeitos de obturações com amálgama sobre a saúde de crianças não devem ser a base de decisões quanto à escolha de materiais de restauração dentária. 
Essa lupa sobre o universo da pesquisa é esclarecedora e chama a atenção sobre a manipulação a que estamos expostos, bem como para o fato de que precisamos reflexivamente nos voltar para a amplitude de problemas que estruturam a identidade-ética do cirurgiãodentista e a prática odontológica na saúde bucal coletiva. Sobre a questão amálgama versus resina composta e derivados, como os selantes de fóssulas e fissuras dentais, não se pode deixar de ignorar que o uso das resinas é menos invasivo aos tecidos dentários e que o mercúrio é substância tóxica. Pensamos que a substituição do amálgama odontológico seja questão de tempo, em função do aumento das práticas de promoção da saúde bucal, da estética proveniente das resinas e de sua própria evolução. O amálgama, entretanto, quando bem indicado e usado, ainda é material que deve e pode ser adotado, principalmente na saúde bucal coletiva, dados sua durabilidade e seu custo.

As bem articuladas e envolventes estratégias para abraçar o novo na odontologia fazem esquecer, por exemplo, o quanto as restaurações de amálgama foram importantes para sua prática, enfatizando traços do avanço e do que está na moda, celebrando o envolvimento da sedução e da razão produtiva, instrumental e operacional, visando à atração no mercado consumidor odontológico. Por exemplo, no plano estritamente da vaidade, destaca-se o uso do piercing dental. Alguns cirurgiões-dentistas se prestam a colocar esse artefato estético, reedição de uma prática cultural do povo maia: crânios do século IX apresentam numerosas incrustações de jade e turquesa, com o propósito de adorno, e mutilação dos dentes com propósitos religiosos (Ring, 1989). É muito particular essa atividade dos ancestrais maias e as transformações que o objeto odontológico vem passando, para atender aos desejos dos consumidores.

Essas novidades que a forma mercadoria odontológica apresenta no processo de trabalho, dispensando práticas do passado recente, como o uso das restaurações de amálgama, e assimilando práticas como a colocação de piercing dental, têm interconexões e afinidades em sua conformação mercantil atual. Neste caso, o valor não está apenas no aspecto econômico (puro), mas também no modo como o cirurgião-dentista ontologicamente se expressa na forma social (total) de seu trabalho, como produto da práxis odontológica contemporânea. Segundo Marx (1987), a mercadoria é misteriosa simplesmente por encobrir os aspectos sociais do próprio trabalho, ignorando-se a interação humana que está por trás dos produtos do trabalho. Chama a isso 'fetichismo da mercadoria', que, por ação e/ ou omissão, oculta a relação social implícita na compra e venda da capacidade de trabalho, na produção de mercadorias na sociedade capitalista.

O objeto odontológico e seu caráter polissêmico (mercadorias) é um segredo de sua própria criação social, pois a conversão dos objetos úteis em valores é, como a linguagem, um produto social dos homens. Carvalho (jan.-mar. 2006) argumenta muito bem que já no século XVIII, nos Estados Unidos e na Inglaterra, as transformações nos modos de vida da sociedade emergente foram caracterizadas pelo modismo e pela preocupação com a estética e elegância, sendo as primeiras estratégias usadas pelos cirurgiões-dentistas para expansão da demanda e do mercado, sem ênfase na necessidade vital.

A odontologia da vaidade perde seus limites no ato da colocação de um piercing dental, assumindo significado cuja utilidade banaliza a compreensão do processo saúde/doença, tendo como produto social a veneração da beleza e da vaidade, distanciando-se ainda 
mais da percepção coletiva de seu objeto sociedade. A interface entre os labirintos da forma mercadoria e a construção do pensamento odontológico, como 'constituição fetichista', propicia via de acesso mais fácil e eficaz a toda problemática contemporânea odontológica com a crítica radical do valor, como crítica da sociedade contemporânea, com a identidade social do cirurgião-dentista produzida e interligada entre sua forma de existência na realidade do mundo (ontologia) e a representação de seu pensamento (epistemologia).

A identidade, de acordo com Bauman (1998), possui várias dimensões na modernidade tardia. A incerteza dissimula laços em encontros sucessivos, fragmentos, tendo as identidades, como máscaras descartáveis, história de vida numa série de episódios em que a arte de esquecer é condição de contínua adaptação ao fluxo permanente de coisas e pessoas. Já não se procura mais construir a identidade vivida num mundo voltado para a constituição da ordem.

Nesse contexto, a racionalidade tem seu funcionamento na efemeridade, no que é acelerado, fugaz, na frivolidade, em que a objetividade se institui com um verdadeiro espetáculo, em que o domínio técnico se reconcilia com o lúdico, e o domínio político, com a sedução (Lipovetsky, 2004). Referências e nexos revelados, quanto à estética odontológica aplicada às identidades dos consumidores, contribuem para fixar sua efêmera identidade racional, mantê-la e transformá-la, pois somos não o que somos, mas o que fazemos de nós mesmos. Os ávidos consumidores por esses tratamentos e a odontologia estão promovendo a ressurreição dos 'maias da modernidade tardia'.

O corpo parece ter assumido a função de representar o 'eu interior' (self) (Giddens, 2002), com pressões condicionantes sobre os indivíduos, como o "sorriso de sucesso" com "dentes brancos", para que sigam determinantes normativos em relação à aparência externa, ao visual. $\mathrm{Na}$ atualidade, vigora a idéia do corpo como produto que pode ser remodelado de acordo com a moda, com o poder de decisão do consumidor que, ao lidar com as informações dos muitos experts odontológicos disponíveis no mercado, vive sob a égide da 'indústria do corpo'. O consumismo encarna a noção do indivíduo autônomo, racional, 'egoísta-narcisista', que é impulsionado primordialmente por expectativas de prazer e ganho derivadas de sua participação no mercado.

Nesse contexto narcísico, a denúncia e 'metáfora epidemiológica' apresentada pela banda Titãs, com a música de Fromer e Reis (1987) "Jesus não tem dentes no país dos banguelas", nos possibilita fazer interessante contraponto com estes dados do Projeto SB - Brasil, relativos a 2003: 14,4\% dos brasileiros já perderam todos os dentes; trata-se, portanto, de um exército de pessoas, com nada menos que 26,6 milhões de desdentados. Esse problema atinge, de forma muito mais agressiva, a população de alto risco, que é a de baixa renda $(17,5 \%)$, mas não exclui quem tem o 'bolso mais cheio' (5,9\%) (Brasil, 2004). A história que se tem é visível e previsível, e é uma referência para tornar inteligível o que emerge retratado no campo da cultura musical e popular, com o objeto odontológico relacionado à exclusão social, com o corpo (dentes) sendo negado socialmente.

Mesmo diante dessa realidade epidemiológica, os cirurgiões-dentistas recém-formados ainda buscam clientela com perfil muito parecido, vinculada às classes média e alta. A procura de pacientes com esse perfil, porém, já apresenta sinais de saturação, como prova a bocastreet (Emmerich, 2004), metáfora que circula em meio aos cirurgiões-dentistas, 
relacionada com a proliferação de consultórios ou clínicas odontológicas ao longo da Avenida Reta da Penha, em Vitória, reduto da classe com maior renda na capital do estado do Espírito Santo. Essa metáfora urbano-odontológica pode ser generalizada para outros grandes centros do país, com a disputa por consumidores de maior poder aquisitivo, direcionando a vida privada e a inserção profissional do cirurgião-dentista para a sociedade de consumo.

O objeto odontológico (hollywood smile) dos desejos e das vaidades dos consumidores é central na construção intersubjetiva do cirurgião-dentista e do paciente, e se institui não como direito ou prazer do indivíduo, mas como dever a ser cumprido. Num mundo assim, repleto de objetos projetados para imediata obsolescência, as identidades são mutantes, ambivalentes, podendo ser adotadas e descartadas, tornando-se permanente devir.

\section{Uma conclusão provisória}

Diante do polissêmico objeto odontológico, fomos levados, ao longo deste ensaio, à exploração do papel do outro, o paciente, na construção do objeto odontológico e de sua relação com o sujeito cirurgião-dentista no mundo contemporâneo. Como visto, o fenômeno da individuação do cirurgião-dentista com seu objeto, sendo isolado, perturbado e fragmentado, circula em torno de uma ontologia petrificada, estando no presente momento, sob forte influência dos consumidores, confluindo na odontologia dos desejos e das vaidades. É em sua intersubjetividade com o consumidor/paciente e consigo próprio que se vão internalizando papéis, conhecimentos e funções sociais, o que permite a formação da idéia de si mesmo e de seu objeto.

Algumas tarefas são inadiáveis para construir referências e transformações do objeto odontológico. Em primeiro lugar está a nova perspectiva para o cirurgião-dentista no Programa de Saúde da Família (PSF), estratégia fundamental do modelo assistencial básico à saúde dos brasileiros no SUS. O desafio é produzir um profissional comprometido com visão ampliada sobre o objeto de sua prática como coletivo, em contexto de determinação social da saúde, capaz de entender os usuários, levando em consideração os vários aspectos de sua vida, condicionantes da saúde e não apenas um conjunto de sinais e sintomas restritos à saúde bucal. Com isso, o serviço público torna-se daqui para a frente importantíssimo mercado de trabalho; os cirurgiões-dentistas, entretanto, continuam sendo graduados e portadores de subjetividade descontextualizada voltada para os desejos e as vaidades dos consumidores. Ceccin e Feuerwerker (2004) formularam uma estratégia no campo da formação no SUS, na perspectiva da reforma sanitária brasileira, com análise da integralidade da atenção à saúde e a necessidade de mudança na formação dos profissionais desde a graduação para contribuir com a política do SUS. Com a tentativa de minimizar a lacuna existente entre o perfil atual do cirurgião-dentista e o de profissional que atenda realmente às necessidades da população, o governo federal formulou política de reordenação na formação de recursos humanos, o Programa Nacional de Reorientação da Formação Profissional em Saúde (Pró-Saúde), fornecendo subsídios para novo perfil profissional comprometido com a situação epidemiológica verificada em sua região de atuação. Esse programa pressupõe a integração de ensino e serviço, otimizando ao atendimento da sociedade (Brasil, 2007). Haddad e Morita (2006), analisando o Pró-Saúde e suas perspectivas 
para a odontologia, acreditam que o conhecimento acumulado na academia possa influenciar diretamente as práticas de saúde, que, por sua vez, poderão ampliar as perspectivas do meio acadêmico tanto no ensino quanto na pesquisa. Aerts, Abegg e Cesa (2004) acrescentam que os serviços odontológicos promotores de saúde exigem a presença de profissionais com visão ampliada sobre o processo saúde/doença. São referências reflexivas para que o objeto odontológico possa traduzir-se, transformar-se e se complementar como objeto coletivo.

Em segundo lugar, como a ciência odontológica hegemônica está relacionada com a odontologia de mercado, Kurz (1998) chama a atenção para o fato de que não se deve esperar que a ciência, como ramo institucional da modernidade burguesa, invista contra seus próprios fundamentos e dê, por si mesma, o próximo passo histórico do pensamento, isto é, que passe à crítica radical da forma mercadoria. É fundamental reconhecer que grande parte dos cientistas, pesquisadores e trabalhadores da saúde bucal estão descentrados e intimamente moldados à forma mercadoria consumista, instituída, nessa medida, por segmentos acadêmico-profissional-associativos envolvidos com o capitalismo consumista. Será o fim do uso do amálgama de prata na prática odontológica? Vimos que em termos de custo/benefício, ele é viável e recomendável.

De acordo com o pensamento de Marx (1987), no valor de uso das mercadorias nada é misterioso, sejam elas observadas sob o aspecto da satisfação de necessidades humanas ou sob o ângulo do trabalho humano. É evidente que o cirurgião-dentista modifica do modo que lhe é útil a forma dos elementos que usa em seu processo de trabalho. Modifica, por exemplo, o uso que foi destinado biotecnologiamente às resinas compostas para reconstruir dentes atacados pela cárie dentária ou fraturas dentárias, promovendo a colagem de um simples piercing à superfície dental com finalidade completamente diferente daquela para que foi industrialmente planejado.

Acreditamos que a produção sócio-histórica odontológica e seu imaginário (Castoriadis, 1986; Emmerich, 2000) relacionam-se com o produto social próprio do trabalho que permite a criação das mercadorias pelos cirurgiões-dentistas, que parecem dotados de vida própria, figuras autônomas que mantêm relações entre si e com o consumidor/paciente, completando-se. Os produtos desse trabalho no mundo das mercadorias odontológicas desempenham papel 'fetichizado', como um 'agente de união' grudados às novas mercadorias dos desejos e das vaidades, encobrindo as características sociais do trabalho odontológico e as influências que ele recebe na sociedade contemporânea, ocultando a relação social existente quanto a sua produção. Marx (1987) assinala uma dissimulação na qual os produtos do trabalho se tornam mercadorias, coisas sociais, com propriedades perceptíveis e imperceptíveis aos sentidos, assumindo a forma 'fantasmagórica' entre coisas.

Finalmente, a individuação sócio-histórica do cirurgião-dentista e o fetichismo, na acepção marxista, estimulam o surgimento de uma crítica à forma mercadoria odontológica, configurando uma crise de identidade do cirurgião-dentista, com mudanças que são incertas, fragmentadas e fugazes. Parafraseando Fromer e Reis (1987), Jesus tem dentes metal-free no país dos banguelas? O que virá depois da odontologia dos desejos e das vaidades? Alcançaremos a produção de dentes humanos bioengenheirados? Seremos capazes de evitar que a odontologia seja universalmente uma profissão descontextualizada, sem objetivos coletivos, desumana e particularizada? 


\section{REFERÊNCIAS}

AERTS, Denise; ABEGG, Claídes; CESA, Kátia. O papel do cirurgião-dentista no Sistema Único de Saúde. Ciência \& Saúde Coletiva, Rio de Janeiro, v..9, n.1, p.131-138. 2004.

BAUMAN, Zygmunt.

O mal-estar da pós-modernidade. Rio de Janeiro: Jorge Zahar Editor.1998.

BELLINGER, David C. et al.

Neuropsychological and renal effects of dental amalgam in children. JAMA, Chicago, v.295, n.15, p.1.775-1.783, 2006.

BOTAZZO, Carlos.

Sobre a bucalidade: notas para a pesquisa e contribuição ao debate. Ciência \& Saúde Coletiva, Rio de Janeiro, v.11, n.1, p.7-17, 2006.

BRASIL.

Programa Nacional de Reorientação da Formação Profissional em Saúde - Pró-Saúde: O SUS e a formação de Recursos Humanos em Saúde. Brasília: Ministério da Saúde/Ministério da Educação. Disponível em: http://www. prosaude.org/pub/sus_frhs/index.php. Acesso em: 12 fev. 2007. 2007.

BRASIL.

Ministério da Saúde. Secretaria de Atenção à Saúde. Departamento de Atenção Básica. Projeto SB Brasil 2003: condições de saúde bucal da população brasileira 2002-2003 - resultados principais. Brasília: Ministério da Saúde. 2004.

CARVALHO, Cristina Leite.

A transformação no mercado de serviços odontológicos e as disputas pelo monopólio da prática odontológica no século XIX. História, Ciências, Saúde - Manguinhos, Rio de Janeiro, v.13, n.1, p.55-76. jan.-mar. 2006.

CASTIEL, Luis David.

A medida do possível... saúde, risco e tecnobiociências. Rio de Janeiro: Fiocruz. 1999.

CASTORIADIS, Cornelius.

A instituição imaginária da sociedade. 2.ed. Rio de Janeiro: Paz e Terra. 1986.

CECCIN, Ricardo Burg; FEUERWERKER, Laura C. Macruz.

Mudança na graduação das profissões de saúde sob o eixo da integralidade. Cadernos de Saúde Pública, Rio de Janeiro, v.20, n.5, p.1.400-1.410. 2004.

COPPA, A. et al.

Paleontology: Early Neolithic tradition of dentistry. Nature, London, n.440, p.755-756. 2006.

EMMERICH, Adauto.

Saúde bucal x bocastreet. A Gazeta, Vitória. 19 out. 2004.
EMMERICH, Adauto.

A corporação odontológica e o seu imaginário. Vitória: Edufes. 2000.

FROMER, Marcelo; REIS, Nando. Jesus não tem dentes no país dos banguelas. São Paulo. Disponível em: http://www.titas.net/ discografiaindex.php?acao=letra\&faixa_id $=40 \&$ obra_id=43\&inte. Acesso em: 23 jun. 2006. 1 disco sonoro. 1987.

GIDDENS, Anthony.

Modernidade e identidade.

Rio de Janeiro: Jorge Zahar Editor. 2002.

GOLDACRE, Ben.

Good news you didn't read on mercury fillings. Disponível em: http://www.guardian.co.uk/life/ badscience/story/0,,1768881,00html. Acesso em: 9 maio 2006. s.d.

HADDAD, Ana Estela; MORITA, Maria Celeste. O ensino da odontologia e as políticas de saúde e de educação. In: Carvalho, Antonio César Perri; Kriger, Léo (Org.). Educação odontológica. São Paulo: Artes Médicas. p.105-117. 2006.

KURZ, Robert.

Os últimos combates. 5.ed. Petrópolis: Vozes. 1998.

LATOUR, Bruno.

A esperança de Pandora. Bauru: Edusc. 1999.

LE GOFF, Jacques.

Os intelectuais na Idade Média. Rio de Janeiro: Brasiliense. 1988.

LEITE, Marcelo. Volta por cima do amálgama. Disponível em: http://www.cienciaemdia. zip.net/index.html. Acesso em: 9 mai. 2006. s.d.

LIPOVETSKY, Gilles.

O império do efêmero. São Paulo: Companhia das Letras. 2004.

MARTIN-BARBERO, Jesús.

Dos meios às mediações. Rio de Janeiro: UFRJ. 1997.

MARX, Karl.

O capital. Rio de Janeiro: Bertrand Brasil. 1987.

MEIRA, Antônio José de. J.

Modelo de atenção odontológica simplificada a escolares. Belo Horizonte: SES; Finep; PUC-MG. 1985.

NARVAI, Paulo Capel.

Saúde bucal coletiva: um conceito. Odontologia e Sociedade, São Paulo, v.3, n.1/2, p.47-52. 2001.

NARVAI, Paulo Capel.

Odontologia e saúde bucal coletiva. São Paulo: Hucitec. 1994. 
OFFENBACHER, Steven; BECK, James D. Medicina Periodontal: o papel da infecção periodontal no estresse sistêmico, doença cardiovascular e nos resultados anormais da gestação. In: Brunetti, Maria Christina (Org.). Periodontia médica: uma abordagem integrada. São Paulo: Senac. p.113-148. 2004.

PAYARES GONZÁLEZ, Carlos.

Es la práctica odontológica un trabajo social descontextualizado? Revista Cubana Estomatol, Habana, v.34, n.2, p. 96-102. 1997.

\section{PLÁSTICA...}

Plástica \& beleza. Disponível em: http://plastica ebeleza.terra.com.br/default.asp. Acesso em: 30 maio 2006. s.d.

QUALIDADE DE VIDA...

Qualidade de vida (e os grandes prazeres) começam pela boca. Cuide dela. Veja, São Paulo, n.1909. jun. 2005.
RING, Malvin E.

História de la odontologia. Barcelona: Doyma. 1989.

SCHAPIRA, Marta V.

La odontología en Argentina: historia de una profesión subordinada. História, Ciências, Saúde - Manguinhos, Rio de Janeiro, v.10, n.3, p.955977. set.- dez. 2003.

SENNETT, Richard.

A cultura do novo capitalismo. Rio de Janeiro: Record. 2006.

SHARPE, Paul T.; YOUNG, Conan S.

Dentes de proveta. Scientific American, New York, n.40, p.70-77. 2005.

SILVERMAN JR., Sol; EVERSOLE, L. Roy; TRUELOVE, Edmond L.

Fundamentos de medicina oral. Rio de Janeiro: Guanabara Koogan. 2004. 